\title{
Avaliação preliminar de óleos essenciais de plantas como repelentes para Aedes albopictus (Skuse, 1894) (Diptera: Culicidae)
}

\author{
BUENO, V.S. ${ }^{1}$; ANDRADE, C.F.S. ${ }^{*}$ \\ ${ }^{1}$ Universidade Franciscana, CEP: 12916-900, Bragança Paulista-Brasil ${ }^{2}$ Departamento de Biologia Animal, \\ UNICAMP, Caixa Postal 6109, CEP: 13083-970, Campinas-Brasil *cfeandra@unicamp.br
}

\begin{abstract}
RESUMO: Óleos essenciais de plantas têm sido formulados de forma caseira ou colocados no mercado de forma artesanal para repelir mosquitos hematófagos. O presente trabalho avaliou 0 possível efeito repelente de alguns excipientes normalmente usados em formulações comerciais e de óleos essenciais de nove plantas, sobre fêmeas de Aedes albopictus. Os testes foram realizados em caixas contendo mosquitos, oferecendo-se uma área definida de dedos da mão tratados ou não. Exceto pelo creme Lanatte e os géis de carbopol, as substâncias excipientes avaliadas mostraram ação repelente. Apenas os óleos provenientes de citronela (5 e 10\%) resultaram em repelência expressiva, com índices médios de proteção acima de $98 \%$. Os resultados indicam que a metodologia empregada é adequada para a avaliação preliminar de produtos com potencial para a repelência de mosquitos.
\end{abstract}

Palavras-chaves: bioensaio, repelência, mosquito, óleos essenciais

\begin{abstract}
Preliminary evaluation of plant essential oils as repellents against Aedes albopictus (Skuse, 1894) (Diptera: Culicidae). Plant essential oils have been domestically formulated or marketed as handcraft products to repel hematophagous mosquitoes. This work evaluated the possible repellent effect of both excipients normally used in commercial formulations and essential oils from nine plants against Aedes albopictus females. The assays were carried out in boxes containing mosquitoes, where a defined area of treated or non-treated fingers was offered. Except for Lanatte cream and carbopol gels, the evaluated excipients had repellent action. Only the oils from citronella ( 5 and $10 \%$ ) presented expressive repellent action, with mean protection indexes above $98 \%$. The results indicate that the used methodology is appropriate for the preliminary evaluation of products with potential to repel mosquitoes.
\end{abstract}

Key words: bioassay, repellence, mosquito, essential oils

\section{INTRODUÇÃO}

O uso de plantas como repelentes de insetos foi citado na literatura greco-romana, onde Caio Plínio, 'o velho' (23-79 a.D.) e o médico Dioscorides (c. 5070 a.D.) registram o uso de losna (Artemisia absinthium L.) (Compositae) como repelente de mosquitos e pulgas. Caio Plínio também descreve em sua obra 'História Natural' a utilização de folhas e frutos da cidra, Citrus medica Risso (Rutaceae), como repelentes em roupas armazenadas (Gupta \& Rutledge, 1994).

Em algumas regiões da Índia, como Jeypore e Madras, as mulheres aplicam diariamente cúrcuma (Curcuma longa L., Zingiberaceae) em óleo vegetal para proteção contra mosquitos. No México, o urucum (Bixa orellana L., Bixaceae) dissolvido em óleo vegetal ou animal, é utilizado como repelente pela população contra mosquitos e outros insetos durante pescarias, no trabalho agrícola ou mesmo nas moradias (Mom, 1948; Gupta \& Rutledge, 1994)

Desde o início do século $X X$, vários produtos naturais foram utilizados como repelentes de insetos. Atualmente entre os repelentes botânicos mais avaliados estão o piretro [Tanacetum cinerariaefolium Trev. (Asteraceae)] a citronela (Cymbopogon nardus (L.) Rendle, Gramineae) e a andiroba [Carapa guianensis Aublet. (Meliaceae)].

A descoberta da citronela e da andiroba como repelentes para a pele tem gerado vários produtos com eficiência inferior ou inicialmente até similar ao DEET (N,N-Dietil-meta-toluamida) ou ao

Recebido para publicação em 28/04/09

Aceito para publicação em 15/12/09

Rev. Bras. Pl. Med., Botucatu, v.12, n.2, p.215-219, 2010. 
IR3535 (etil-butil-acetilaminopropionato), que são os ingredientes ativos sintéticos mais usados comercialmente (Miot et al., 2004; Andrade, 2005; 2008), e permitido patentes registradas na França, Japão, União Européia e Estados Unidos.

Também é crescente o número de velas e incensos (defumadores) que utilizam a citronela ou a andiroba como repelentes ambientais. Porém, só possuem atividade efetiva em áreas internas de ambientes não completamente fechados (Gupta \& Rutledge, 1994), sendo essa uma das recomendações presentes nos rótulos dos produtos.

Afora o desenvolvimento de produtos para o mercado, a manufatura e uso comunitário de repelentes à base de plantas vêm sendo propostos pelo Programa das Nações Unidas para o Meio Ambiente (OMS, 1993), sendo as misturas do óleo de citronela e do álcool canforado indicado como repelentes contra mosquitos e flebotomíneos.

Muitos são os estudos realizados com fitoquímicos para controle de pragas agrícolas e insetos de importância médica, e boa revisão pode ser encontrada em Evans (1996). Mais recentemente Freire et al. (2006) avaliaram a andiroba e a copaíba como repelentes de forídeos, pragas de colméias na Amazônia, indicando como boa alternativa no controle preventivo e curativo dessa praga em colônias de Meliponineos.

No presente trabalho pretendeu-se avaliar o potencial repelente de óleos essenciais extraídos de vegetais diluídos em solvente, e ainda de oito excipientes sobre Aedes albopictus, utilizando-se uma metodologia para triagem inicial em laboratório.

\section{MATERIAL E MÉTODO}

Inicialmente comparou-se o efeito repelente de etanol puro e a $70 \%$ com o do éter etílico absoluto, embora na maioria dos trabalhos seja utilizado o etanol como diluente de substâncias oleosas com potencial repelente (Schreck \& McGovern, 1989; Annis, 1991; Frances et al., 1993).

As diluições dos óleos essenciais foram feitas procurando-se manter a concentração próxima àquela obtida durante a extração da planta.

Alguns óleos e outras bases também consideradas inertes foram testados para 0 conhecimento da influência como excipientes na formulação de repelentes. Avaliou-se o óleo de canola, óleo de milho, óleo mineral puro (Nujol $\left.{ }^{\circledR}\right)$, vaselina líquida, óleo de silicone, creme aniônico Lanette e dois géis à base de carbopol $(0,5$ e $1 \%$ de polímero aniônico carboxivinílico).

As espécies de plantas utilizadas no presente trabalho, bem como, as partes usadas para a extração e as concentrações dos óleos essenciais avaliadas foram: 1 - citronela -Cymbopogon nardus (L.)
Rendle (Gramineae), partes aéreas a 0,8; $1 ; 5$ e 10\%, 2- capim-limão - Cymbopogon citratus (DC) Stapf (Gramineae), partes aéreas a 1\%, 3- arruda - Ruta graveolens L. (Rutaceae) partes aéreas a 1,0\%, 4eucalipto - Eucalyptus globulus Labill. (Myrtaceae) folhas a $2 \%, 5$ - erva-de-santa-Maria - Chenopodium ambrosioides L. (Chenopodiaceae) a 1\%, 6manjericão - Ocimum basilicium L. (Labiatae,) partes aéreas a 1\%, 7- alecrim-de-cheiro - Rosmarinus officinalis $\mathrm{L}$. (Labiatae) partes aéreas a 1\%, 8- poejo - Mentha pulegium L. (Labiatae) partes aéreas a 1\% e 9- andiroba - Carapa guianensis Aubl. (Meliaceae) folhas a $5 \%$. Os óleos foram extraídos conforme método descrito na Farmacopéia Brasileira utilizandose extrator de Clevenger modificado e as formulações foram feitas sem fixador.

Avaliou-se o número de tentativas de picadas de fêmeas do mosquito Aedes albopictus (Skuse, 1895), Linhagem Unicamp, estabelecida a partir de coletas em Campinas, SP e mantida no laboratório desde 1997. As avaliações foram feitas em área de $8 \mathrm{~cm}^{2}$ de pele dos dedos das mãos dos pesquisadores, em pares de dedos tratados e não tratados (controle), aplicando-se um volume de $20 \mathrm{~mL}$ do produto excipiente ou da solução de óleo essencial. Exceto pela área dos dedos, os braços e as mãos foram protegidas por luvas plásticas e introduzidas em caixas com pelo menos 50 fêmeas de $A$. albopictus nunca alimentadas de sangue, em ambiente com temperatura $\left(25 \pm 2^{\circ} \mathrm{C}\right)$ e umidade relativa do ar $(80 \pm 5 \%)$ controladas. Foram feitas em dias diferentes, seis repetições de 15 minutos cada para a avaliação das amostras (Andrade \& Bueno, 2001). O índice de proteção (\%) foi determinado a partir do número médio de picadas no controle e no tratamento baseando-se na fórmula de Abbott (Rutledge et al., 1985; Mani et al., 1991; Combemale et al., 1992). Utilizou-se análise de variância e o teste de Tukey ao nível de significância de $5 \%$ para a análise estatística usando-se o programa BioEstat 5.0.

\section{RESULTADO E DISCUSSÃO}

Os solventes testados (para análise) foram evaporados e apresentaram $0,001 \%$ de resíduos após a evaporação. Para os 15 minutos de avaliação de repelência dos solventes, o número médio de picadas em dedos não tratados foi de 58,8 (DP=11,2). O éter etílico mostrou-se mais satisfatório devido a rápida evaporação quando em contato com a pele humana e por apresentar discreta e não significativa ação repelente $(15,4 \%)$ quando comparado a dedos sem tratamento algum. Já o etanol absoluto e o etanol a $70 \%$ permitiram acima de $50 \%$ de repelência diferindo significativamente $(p<0,05)$, tanto do tratamento com éter como do controle. Baseado nesses resultados

Rev. Bras. Pl. Med., Botucatu, v.12, n.2, p.215-219, 2010. 
utilizou-se o éter etílico para as diluições dos óleos essenciais.

$\mathrm{Na}$ avaliação dos excipientes, a média de picadas em dedos não tratados foi de 28,5 (DP=19,7) e a maioria dos produtos permitiu elevada proteção, embora não tenha sido detectada diferença estatística entre os materiais. De forma decrescente a vaselina foi a que mais evitou as picadas $(97,5 \%)$, seguida pelos óleos de silicone (96,3\%), canola $(93,1 \%)$, óleo mineral $(92,4 \%)$ e óleo de milho $(88,2 \%)$. O número de picadas nos dedos tratados com o creme Lanatte ou com os dois géis de carbopol foi elevado, não diferindo entre eles ou do controle $(p>0,05)$ e indicando ausência de repelência (Tabela 1). Sabe-se que algumas dessas substâncias são utilizadas como veículo na preparação de repelentes caseiros ou produtos artesanais e pode-se, portanto atribuir esses efeitos repelentes, em grande parte, ao óleo utilizado como veículo e não à planta em si.

$\mathrm{Na}$ avaliação dos óleos essenciais diluídos em éter etílico, o número médio de picadas em dedos sem tratamento foi de 52,9 (DP=13,6). Os óleos de citronela a 5 e 10\% apresentaram uma ação repelente expressiva, com índices médios de proteção de $98,1 \%$ e $99,0 \%$ respectivamente. O tratamento com óleo de alecrim-de-cheiro também se mostrou repelente com índice de $84,1 \%$. Os óleos de eucalipto $(72,7 \%)$, manjericão $(68,5 \%)$ e poejo $(66,4 \%)$ permitiram repelência intermediária sem diferença significativa, seguidos dos óleos de erva-de-Santa-Maria e citronela a 1\%, com índices de proteção de $53,5 \%$ e 52,9\% respectivamente. Os demais óleos essenciais mostraram índices de proteção abaixo de $40 \%$, indicando baixa repelência (Tabela 2).

De acordo com Barnard (2005) e Barnard et

TABELA 1. Número médio de picadas (Desvio Padrão) e índice de proteção para substâncias utilizadas como excipiente na formulação para avaliação de repelentes.

\begin{tabular}{lrrc}
\hline Produto & \multicolumn{1}{c}{ Tratamento } & \multicolumn{1}{c}{ Controle } & $\begin{array}{c}\text { Índice de proteção } \\
(\%)\end{array}$ \\
Vaselina & $0,5(1,0) \mathbf{a}$ & $19,7(2,5) \mathbf{b}$ & 97,5 \\
Óleo de silicone & $0,7(0,9) \mathbf{a}$ & $18,7(5,3) \mathbf{b}$ & 96,3 \\
Óleo de canola & $1,8(2,8) \mathbf{a}$ & $26,2(7,2) \mathbf{b}$ & 93,1 \\
Óleo mineral & $1,6(1,7) \mathbf{a}$ & $21,1(7,3) \mathbf{b}$ & 92,4 \\
Óleo de milho & $2,0(1,4) \mathbf{a}$ & $17,0(1,4) \mathbf{b}$ & 88,2 \\
Creme Lanatte** & $17,5(4,0) \mathbf{a}$ & $18,0(4,3) \mathbf{a}$ & 2,8 \\
Gel carbopol 0,5\% & $78,0(21,0) \mathbf{a}$ & $76,0(14,0) \mathbf{a}$ & 2,6 \\
Gel carbopol 1,0\% & $29,0(12,3) \mathbf{a}$ & $31,0(10,2) \mathbf{a}$ & 6,5 \\
\hline
\end{tabular}

$\mathrm{Na}$ horizontal, médias seguidas de mesma letra não apresentam diferença estatística significativa (teste de Tukey, $p<0,05$ ).

TABELA 2. Número médio de picadas (Desvio Padrão) para o tratamento com extratos vegetais, para o controle sem nenhuma aplicação e Índices de Proteção calculados.

\begin{tabular}{|c|c|c|c|}
\hline $\begin{array}{c}\text { Planta utilizada } \\
\text { (concentração do extrato \%) }\end{array}$ & Extrato & Controle & $\begin{array}{c}\text { Índice de Proteção } \\
(\%)\end{array}$ \\
\hline Citronela $(0,8)$ & $38,5(16,9) a$ & $63,8(11,3) a$ & 39,7 \\
\hline Citronela $(1,0)$ & $14,0(4,8) \mathrm{a}$ & $29,7(12,6) \mathbf{a}$ & 52,9 \\
\hline Citronela $(5,0)$ & $0,7(1,4) \mathbf{a}$ & $39,6(16,6) \mathbf{b}$ & 98,1 \\
\hline Citronela $(10,0)$ & $10,5(1,0) a$ & $105,3(14,2) b$ & 99,0 \\
\hline Alecrim-de-cheiro $(1,0)$ & $10,0(1,7) \mathrm{a}$ & $63,5(5,0) \mathrm{b}$ & 84,1 \\
\hline Manjericão $(1,0)$ & $17,3(3,0) a$ & $54,9(3,6) a$ & 68,5 \\
\hline Eucalipto $(1,7)$ & $7,8(6,7)$ a & $28,6(34,0)$ a & 72,7 \\
\hline Poejo $(1,0)$ & $14,0(11,8) \mathbf{a}$ & $41,7(13,0)$ a & 66,4 \\
\hline Erva-de-santa-Maria $(1,0)$ & $24,2(17,2)$ a & $52,0(4,2)$ a & 53,5 \\
\hline Andiroba $(5,0)$ & $60,5(45,9) a$ & $87,0(28,2) a$ & 30,4 \\
\hline Capim Limão $(1,0)$ & $29,7(18,1) \mathbf{a}$ & $33,5(43,1) \mathbf{a}$ & 11,3 \\
\hline Arruda $(1,0)$ & $33,4(18,4) \mathbf{a}$ & $35,5(10,6) \mathbf{a}$ & 5,8 \\
\hline
\end{tabular}

Rev. Bras. Pl. Med., Botucatu, v.12, n.2, p.215-219, 2010. 
al. (2007), existem vários protocolos descritos para a avaliação de repelentes de mosquitos e os resultados podem ser afetados pela absorção, penetração, modificação química do repelente na pele, ou ainda pela evaporação, a abrasão e o suor, entre outros fatores ainda. Esses autores indicam ainda que testes simples servem, no entanto, para se obter informações suficientes para selecionar novos compostos para avaliação toxicológica e ensaios de campo.

Usando o mosquito Aedes aegyptiem testes com olfatômetro, Chou et al. (1997) avaliaram 12 produtos repelentes em pele humana. Dos produtos testados, dois eram compostos de extratos de plantas e continham citronela nas formulações. Tanto o produto de nome "Buzz Away", à base de citronela, cedro, eucalipto e capim-limão em base de álcool e água como o produto "Green Ban" (à base de citronela, cajepute, lavanda, sassafrás, menta, bergamota, soja e óleo da árvore de chá) não demonstraram resultados satisfatórios. Nessas avaliações, os autores consideram como critério o tempo para a primeira picada dos mosquitos, o que ocorreu em torno de 30 minutos para "Green Ban" e cerca de 2 horas para "Buzz Away".

Da mesma forma, no final da década de 1940, Wasicky et al. (1949) demonstraram que o efeito do óleo de citronela, já reconhecido como repelente no Brasil, não ultrapassou 30 minutos quando utilizado em pele humana contra o mosquito Culex quinquefasciatus. Usando como critério os tempos para a primeira e a terceira picadas, Miot et al. (2004) avaliaram nos antebraços de voluntários os tratamentos com DEET ( $[\mathrm{N}-\mathrm{N}]$-diethyl- $m$ toluamide) (a 50\%), óleo de soja refinado e óleo de andiroba puro e a $15 \%$ e observaram que não houve picada no tratamento com DEET até uma hora após a exposição dos antebraços. A mediana da primeira picada nos antebraços sem produto foi de 17,5 segundos e para a terceira picada foi de 40 segundos. Exceto para o DEET e para os braços sem tratamento, o teste permitiu pouca discriminação. Para o tratamento com o óleo de soja esses tempos foram respectivamente de 60 e 101 segundos e para o tratamento com óleo de andiroba pura foi de 56 e 142 segundos, diferindo pouco da andiroba diluída a 15\% (63 e 97 segundos).

Na presente avaliação, o critério do índice de proteção para 15 minutos de exposição e o uso de fêmeas de $A$. albopictus confirmaram ser bons indicadores para a seleção de candidatos a repelentes, permitindo a discriminação entre diferentes óleos essenciais e entre diferentes concentrações do óleo de citronela. Os excipientes frequentemente usados nos produtos caseiros ou artesanais mostraram potencial repelente e devem ser evitados nas formulações desse tipo de avaliação.

\section{REFERÊNCIA}

ANDRADE, C.F.S.; BUENO, V.S. Evaluation of three laboratory methods for the comparative test of mosquito repellents using Aedes albopictus (SKUSE) (Diptera: Culicidae) in Brazil. The Annals of Medical Entomology, v.10, n.2, p.34-40, 2001.

ANDRADE, C.F.S. Repelentes de mosquitos para uso tópico: o quanto são eficientes. Vetores \& Pragas, v.15, p.34-6, 2005.

ANDRADE, C.F.S. Repelentes de Mosquitos - Base Técnica para Avaliação. Artigos Técnicos em Ecologia Aplicada, p.1-9, 2008. Disponível em: <http:// www.ib.unicamp.br/profs/eco_aplicada>. Acesso em: 1 abr. 2009.

ANNIS, B. Comparison of the effectiveness of two deet formulations against Aedes albopictus in the Philippines. Journal of the American Mosquito Control Association, v.7, n.4, p.543-6, 1991.

BARNARD, D.R. Biological assay methods for mosquito repellents. Journal of the American Mosquito Control Association, v.21, n.4, p.12-6, 2005.

BARNARD, D.R. et al. Standard methods for testing mosquito repellents. In: DEBBOUN, M.; FRANCES, S.P.; STRICKMAN, D. (Eds.). Insect repellents: principles, methods, and uses. Boca Raton: CRC Press, 2007. p.103-10.

$\mathrm{CHOU}$, J.T. et al. Evaluation of commercial insect repellents on human skin against Aedes aegypti (Diptera:Culicidae). Jounal of Medical Entomology, v.34, n.6, p.624-30, 1997.

COMBEMALE, $P$. et al. Les insectifuges ou les répellents. Annales de dermatologie et de venereologie, v.119, p.411-34, 1992.

FRANCES, S.P. et al. Response of Anopheles dirus and Aedes albopictus to repellents in the laboratory. Journal of the American Mosquito Control Association, v.9, n.4, p.474-6, 1993.

FREIRE, D.C.B. et al. Efeito dos óleos vegetais de andiroba (Carapa sp.) e copaíba (Copaifera sp.) sobre forídeo, pragas de colméias, (Diptera: Phoridae) na Amazônia Central. Acta Amazonica, v.36, n.3, p.365-8, 2006.

GUPTA, R.K.; RUTLEDGE, L.C. Role of repellents in vector control and disease prevention. American Journal of Tropical Medicine and Hygiene, v.50, n.6, p.82-6, 1994. MANI, T.R. et al. Field efficacy of "Mosbar" mosquito repellent soap against vectors of bancroftian filariasis and japanese encephalitis in southern India. Journal of the American Mosquito Control Association, v.7, n.4, p.565-8, 1991.

MIOT, H.A. et al. Comparative study of the topical effectiveness of the andiroba oil (Carapa guianensis) and DEET 50 percent as repellent for Aedes sp. Revista do Instituto de Medicina Tropical de São Paulo, v.46, n.5, p.253-6, 2004.

MOM, A.M. El empleo de la proteccion antisolar y de los repelentes de insectos en los indigenas latinoamericanos. Revista Argentina de Dermatosifilologia, v.32, p.303-6, 1948.

ORGANIZAÇÃO MUNDIAL DA SAÚDE. Programa de las Naciones Unidas para el Medio Ambiente (PNUMA). Control de insectos y roedores mediante gestión ambiental - un programa de acción comunitaria. 
Genebra: OMS, 1993. 111p.

RUTLEDGE, L.C. et al. Mathematical models of the effectiveness and persistence of mosquito repellents. Journal of the American Mosquito Control Association, v.1, n.1, p.56-62, 1985.

SCHRECK, C.E.; McGOVERN, T.P. Repellents and other personal protection strategies against Aedes albopictus. Journal of the American Mosquito Control Association, v.5, n.2, p.247-50, 1989.

WASICKY, R. et al. Repelentes de mosquitos. Anais da Faculdade de Farmácia e Odontologia da Universidade de São Paulo, v.7, p.297-305, 1949. 